\title{
Relação entre parâmetros biométricos e teores de fenóis totais em Lafoensia replicata Pohl. - Um estudo de caso
}

\author{
Relation between biometric parameters and total phenols contents in Lafoensia replicata Pohl. - \\ A case study \\ I. S. Vieira' ${ }^{1}$ S. S. F. Silva² ;. S. N. Souza²; J. M. Monteiro*1 \\ ${ }^{1}$ Campus Amílcar Ferreira Sobral - CAFS, Universidade Federal do Piauí, 64808-605, Floriano - Piauí, Brasil \\ ${ }^{2}$ Campus Profa. Cinobelina Elvas - CPCE, Universidade Federal do Piauí, 63800-000, Bom Jesus - Piauí, Brasil
}

*juliommmonteiro@ufpi.edu.br

(Recebido em 15 de fevereiro de 2017; aceito em 02 de maio de 2017)

\begin{abstract}
Essa pesquisa objetivou avaliar a concentração de fenóis totais nas cascas do caule e folhas da mangabeira (Lafoensia replicata Pohl.), buscando uma correlação com a altura e circunferência do caule dos espécimes estudados. Dez indivíduos da planta foram selecionados em um fragmento de mata em Floriano, Piauí. Para a quantificação do teor de fenóis totais nas amostras foi utilizado o método FolinCiocalteu usando o ácido tânico como padrão. As quantidades de fenóis variaram nas cascas de $L$. replicata Pohl de $11,7 \mathrm{mg}$ a 29,32 mg, variação menor que encontrada nas folhas, 2,60 mg a 33,70 mg. Não houve correlação entre os parâmetros biométricos e os teores de fenóis tanto nas cascas quanto nas folhas. Deve-se orientar a coleta dos recursos da planta para fins terapêuticos somente em indivíduos adultos para assim suportar os danos extrativistas.

Palavras-Chave: mangabeira, aspectos dendrométricos, compostos fenólicos.
\end{abstract}

The objective of this research was to evaluate the concentration of total phenols in the stem bark and leaves of the mangabeira (Lafoensia replicata Pohl.), seeking a correlation with the height and circumference of the stem of the studied specimens. Ten individuals of the plant were selected in a forest fragment in Floriano, Piauí. For quantification of the total phenol content in the samples the FolinCiocalteu method was used using tannic acid as standard. The amounts of phenols varied in the $L$. replicata Pohl. from $11.7 \mathrm{mg}$ to $29.32 \mathrm{mg}$, lower variation than that found in leaves, $2.60 \mathrm{mg}$ to $33.70 \mathrm{mg}$. There was no correlation between the biometric parameters and the phenol content in both bark and leaves. The collection of plant resources for therapeutic purposes should only be guided in adult individuals in order to withstand the extractive damages.

Keywords: mangabeira, dendrometric aspects, phenolic compounds.

\section{INTRODUÇÃO}

Os compostos fenólicos são substâncias que possuem pelo menos um anel aromático cujo hidrogênio é substituído por uma hidroxila e estão vastamente distribuídos no reino vegetal, associados a uma diversa gama de atividades biológicas [1]. Dentre esses compostos com larga atividade biológica, citam-se os taninos e flavonoides. Sendo assim, vários pesquisadores direcionaram suas pesquisas para plantas que sintetizam tais compostos. No Brasil, há várias espécies consideradas importantes pela elevada produção de compostos fenólicos, principalmente elementos arbóreos e que já foram alvo de pesquisas em algumas áreas, como ecologia e química $[2,3,4]$.

Para algumas espécies bem conhecidas no nordeste brasileiro, principalmente na medicina popular, há lacunas no conhecimento científico, como a mangabeira (Lafoensia replicata Pohl.) que é bastante utilizada por sertanejos na terapia popular [5,6]. A fenologia da espécie foi analisada em uma área florestal no município de Bom Jesus, Piauí [7]. Sobrinho et al. (2016) [5] em estudo etnofarmacológico no sudeste do Maranhão, encontraram diversos usos medicinais para a casca do caule e a folha de $L$. replicata e ressaltaram que as folhas podem ser utilizadas 
como um interessante componente medicinal, de acordo com a população estudada. Outros estudos focaram sobre o uso e a atividade biológica da espécie L. pacari A. St.-Hil. A atividade antidepressiva, em ratos, do extrato etanólico das cascas de L. pacari A. St.-Hil. foi encontrada [8]. Esses autores argumentaram ainda sobre a relevância do resultado já que a depressão é um dos males que mais acometem na atualidade, de acordo com a Associação Brasileira de Psiquiatria. Outro estudo, orientado no cerrado brasileiro, Lima et al. (2015) [9] perceberam que o extrato hidroalcoólico da entrecasca de L. pacari A. St.-Hil apresentou atividade leishmanicida significativa, confirmando sua eficácia.

Portanto, considerando a importância de $L$. replicata e tendo em vista a escassez de trabalhos que busquem explicar e apontar as substâncias responsáveis por suas propriedades farmacológicas, essa pesquisa objetivou: determinar a concentração de fenóis totais nas cascas do caule e folhas da mangabeira, bem como associar com a altura e a circunferência do caule. Essa pesquisa preocupa-se em orientar um estudo de prioridades de conservação com base na quantidade de fenóis totais e aspectos biométricos (altura e circunferência do caule). Tudo isso para contribuir com o conhecimento de recursos vegetais medicinais em áreas no semiárido do Sul do Piauí, através de informações fitoquímicas.

\section{MATERIAL E MÉTODOS}

2.1. Coleta das amostras, preparação dos extratos e quantificação dos fenóis totais

A espécie em questão pertence à família Lythraceae, com cerca de 31 gêneros distribuídos entre 600 espécies. No Brasil, há nove gêneros, o Cuphea e o Diplusodon são os mais diversos quanto a número de espécies [10]. O gênero Lafoensia é típico das Américas, marcado por arbustos ou árvores e tem inflorescências terminais em ramos racemiformes a tirsoides com flores de pétalas brancas ou amareladas [11]. Sobre L. replicata há pouca informação disponível. Assim, foi selecionada para estudo por conta de sua alta importância medicinal, utilizada como anti-inflamatória e cicatrizante, bom conhecimento e uso por comunidades tradicionais $[5,6]$ e cujos produtos são obtidos por ações fortemente destrutivas (cascas do caule).

Dez indivíduos de mangabeira foram selecionados em um fragmento de mata em Floriano, Piauí (Figura 1), georreferenciados e coletadas dados como a altura e a circunferência ao nível do peito (CAP). De cada um dos dez espécimes selecionadas, uma amostra de aproximadamente $15 \mathrm{~g}$ foi retirada das cascas do caule (à altura de 1 metro do solo) e das folhas maduras (mesma altura e posição de irradiação solar).

O material botânico foi coletado, herborizado, identificado e depositado no Laboratório de Botânica do Campus Amílcar F. Sobral, Universidade Federal do Piaú́ (UFPI).

Após este processo, foram acondicionadas em saco de papel e levados ao Laboratório de Química da UFPI, campus Prof ${ }^{a}$. Cinobelina Elvas em Bom Jesus, Piauí, para análise dos fenóis totais. Para a quantificação do teor de fenóis totais nas amostras foi utilizado o método FolinCiocalteu usando o ácido tânico como padrão [12-16]. Os tecidos coletados dos indivíduos amostrados foram acondicionados em sacos de papel e levadas a laboratório.

As amostras foram secas a temperatura de $50{ }^{\circ} \mathrm{C}$ durante aproximadamente três dias. Após secas, foram trituradas e os extratos hidrometanólicos $(80 \% \mathrm{v} / \mathrm{v})$ feitos a partir de $500 \mathrm{mg}$ do material para $50 \mathrm{~mL}$ de solvente. Foram realizadas cinco extrações sucessivas sob aquecimento, filtrando o material cada vez que o solvente iniciava a ebulição. Todas as extrações foram realizadas em triplicatas. A partir dos extratos, os teores de fenóis totais foram analisados por meio do método Folin-Ciocalteu [6, 12, 13, 14]. Este método foi empregado no estudo para medir o teor de fenóis totais que consiste na adição de $0,30 \mathrm{~mL}$ do extrato para $75 \mathrm{~mL}$ de água destilada, $5 \mathrm{~mL}$ do reativo de Folin-Ciocalteu (em solução aquosa a $10 \% \mathrm{v} / \mathrm{v}$ ), $10 \mathrm{~mL}$ de carbonato de sódio $(0,75 \% \mathrm{~m} / \mathrm{v})$, completando com água destilada para um volume final de 100 $\mathrm{mL}$. A solução foi mantida em repouso por 30 minutos e medida a absorbância a um comprimento de onda de $760 \mathrm{~nm}$ em um espectrofotômetro. A medida da absorção foi calibrada 


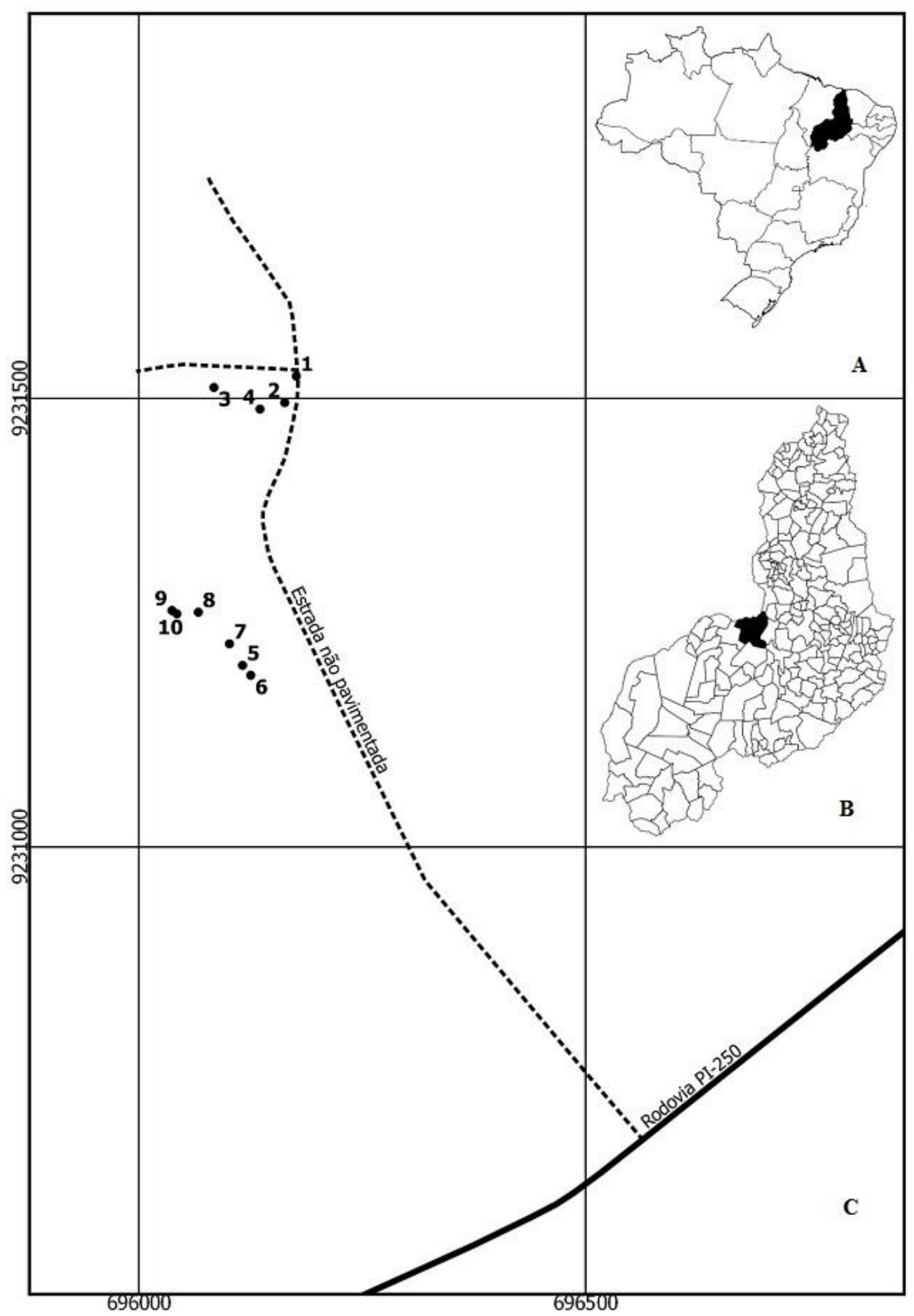

Figura 1. A. Brasil; B. Piauí; C. Localização da área de coleta dos indivíduos de L. replicata Pohl., Município de Floriano, PI. Coordenadas em UTM WGS84

a partir de uma solução controle de ácido tânico nas seguintes concentrações: 0,$1 ; 0,5 ; 1,0 ; 2,5$ e $3,75 \mu \mathrm{g} . \mathrm{mL}-1$. A quantidade de taninos foi expressa em $\mathrm{mg}$ de planta seca (Figura 2). 


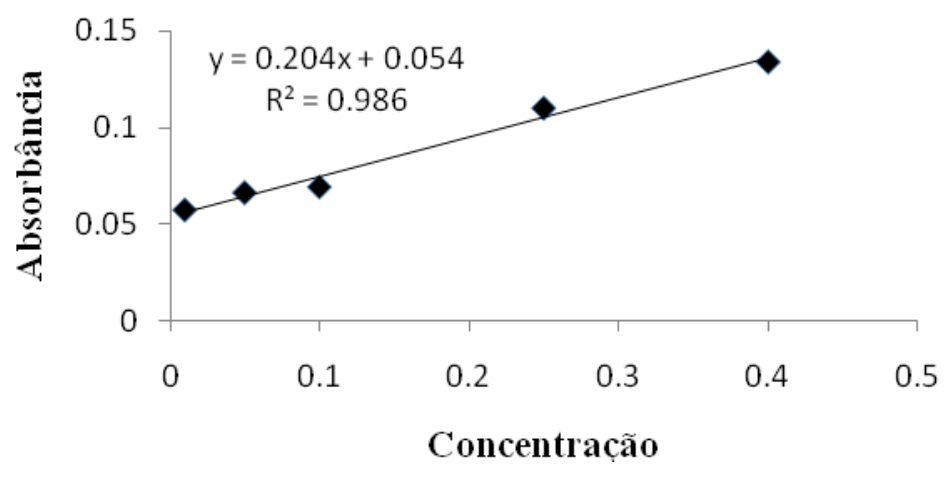

Figura 2. Curva de calibração da concentração de acido tânico em mg. $m L^{-1}$ pela absorbância. Em evidência encontram-se a equação da reta e o erro do ajuste

\subsection{Análise dos dados}

Diferenças na produção de fenóis totais entre folhas e cascas e entre os indivíduos da espécie foram testadas pelo Kruskal-Wallis. O coeficiente de Pearson foi usado para avaliar a correlação entre as alturas, circunferências e teores de fenóis totais. Todas as análises foram realizadas empregando-se o software BIOESTAT 5.0. [18].

\section{RESULTADOS E DISCUSSÃO}

3.1. Teor de fenóis totais dos indivíduos estudados

Os valores médios das quantidades de fenóis totais nas cascas e folhas da espécie estudada estão apresentados na Tabela 1.

Tabela 1. Valores médios de fenóis totais (FT) pelo método Folin-Ciocalteau das cascas e folhas dos indivíduos estudados em relação à altura e a circunferência ao nível do peito (CAP).

\begin{tabular}{ccccc}
\hline Indivíduos & Altura $(\mathbf{m})$ & CAP $(\mathbf{c m})$ & FT $(\mathbf{m g})$ casca & FT (mg) folha \\
\hline 1 & 3,0 & 41,0 & 29,32 & 8,01 \\
\hline 2 & 2,5 & 35,0 & 17,44 & 9,54 \\
\hline 3 & 4,0 & 28,0 & 11,70 & 2,60 \\
\hline 4 & 2,0 & 8,0 & 25,11 & 29,18 \\
\hline 5 & 3,0 & 40,0 & 24,63 & 21,99 \\
\hline 6 & 3,5 & 30,0 & 16,73 & 30,60 \\
\hline 7 & 4,0 & 36,0 & 29,18 & 33,70 \\
\hline 8 & 3,0 & 27,0 & 13,85 & 33,73 \\
\hline 9 & 4,0 & 32,0 & 17,21 & 31,67 \\
\hline 10 & 4,5 & 43,0 & 15,53 & 21,99 \\
\hline
\end{tabular}

A quantidade de fenóis variou intraespecificamente, em relação às cascas e folhas. Variações intraespecíficas na quantidade de fitocompostos químicos são encontradas em várias espécies, de outras famílias botânicas, como já foi documentado para populações de Stryphnodendron adstringens (Martius) Coville [3], M. urundeuva, A. colubrina e $C$. pyramidalis [5]. Tais variações encontradas podem alicerçar a explicação de que alterações individuais/genéticas estejam influenciando os resultados, já que nenhum fator local (solo, 
sombreamento, distância entre os indivíduos, presença de cursos d'água, sinais de herbivoria ou patógenos) pareceu explicar essas diferenças.

As quantidades de fenóis variaram nas cascas de L. replicata de $11,7 \mathrm{mg}$ a 29,32 $\mathrm{mg}(2,20 \%$ a $6,80 \%)$, variação menor que a encontrada nas folhas, $2,60 \mathrm{mg}$ a $33,70 \mathrm{mg}(0,62 \%$ a $7,08 \%)$. Num estudo orientado no Sul do Piauí, Monteiro et al. (2012) [12] verificaram que os taninos, compostos fenólicos de alto peso molecular com a característica de precipitar proteínas, apresentaram pouca variação intraespecífica nas cascas do caule de L. replicata. Os autores encontraram cerca de $7,2 \%$ de taninos totais nas cascas.

Comparando-se a quantidade média de fenóis entre as folhas e cascas da espécie, verificouse que a média da última é ligeiramente menor, contudo, essas diferenças não são significativas $(\mathrm{H}=0,63 ; \mathrm{p}=0,42)$. Monteiro et al. (2005) [6] comparou o teor de taninos, entre cascas e folhas de três importantes espécies medicinais da caatinga e também não verificaram distinções. Esses autores acrescentaram ainda que apesar da alta demanda do uso medicinal das cascas do caule dessas espécies localmente, as folhas sintetizam fenóis em quantidades similares. Ademais, a alta procura e intensa tradição no poder curativo das cascas, provavelmente, ocorrem porque estes recursos mantêm-se disponíveis para as pessoas durante todo o ano. Contudo, devido às similaridades no conteúdo dos compostos fenólicos na espécie deste estudo, a atividade biológica pode se justificar tanto no uso das cascas quanto nas folhas para a ação antiinflamatória.

\subsection{Teor de fenóis totais $X$ parâmetros biométricos}

Encontraram-se diferenças intraespecíficas expressivas tanto para as alturas como para as classes diamétricas na espécie (Tabela 1). Houve variação nas alturas dos indivíduos, de 2,5 a $4,5 \mathrm{~m}$, e CAP de 8,0 a $43 \mathrm{~cm}$.

Na Figura 3 estão correlacionados os teores de fenóis totais com as variáveis analisadas e não houve correlação significante. Portanto, a concentração de fenóis na espécie estudada não se encontra associada com as características biométricas analisadas (Figura 3), como também observou Teixeira et al. (1990) [3] em S. adstringens (Mart.) Coville com relação a classes diamétricas, e para diferentes pontos de coleta ao longo do fuste em A. mearnssi De Wild. [4]. Monteiro et al. (2005) [6] também não encontraram correlação entre taninos e características biométricas em três espécies arbóreas da caatinga. Cabral et al. (2010) [19] investigaram a influência da altura, do diâmetro e da espessura de casca de aroeira (M. urundeuva) e quixabeira (Sideroxylon obtusifolium) com os teores de taninos e fenóis totais, pelos métodos de difusão radial e Folin-Ciocalteau, também não encontraram relação entre as variáveis estudadas.

Em oposição, Silva \& Frizzo (1985) [2] encontraram variação significativa ao longo da altura do caule nos teores de taninos em A. mearnssi De Wild. Num estudo com A. peregrina (L.) Speng., em Lavras, Minas Gerais, Sartori et al. (2014) [20] quantificaram os teores de fenóis totais e taninos nas cascas do caule relacionando com as classes diamétricas, além de comparar duas metodologias de quantificação de fenóis (Folin-Denis e Folin-Ciocalteau). Assim, verificaram que maiores quantidades de fenóis e taninos totais foram encontradas nos indivíduos de maiores classes de diâmetro. Esses autores recomendaram que coletas futuras para a espécie devem ser orientadas levando-se em consideração tais resultados.

Dessa forma, percebe-se que pesquisas futuras são interessantes para clarificar os aspectos que norteiam a síntese e deposição de compostos do metabolismo secundário, pois pode haver variações explicadas por vários fatores como solo, idade, sombreamento, temperatura, disponibilidade hídrica e até variações genéticas individuais [12, 21]. 


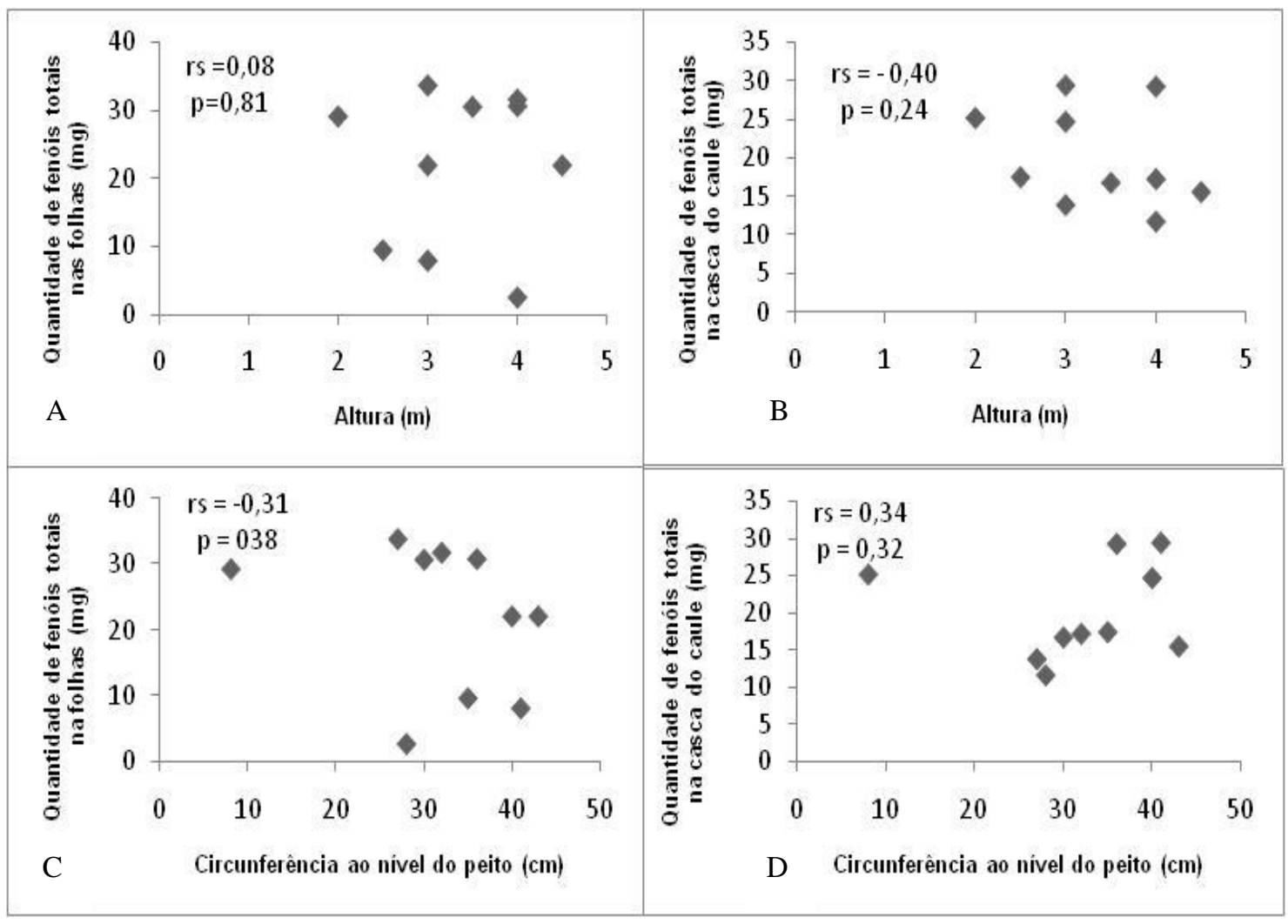

Figura 3. Relação entre a quantidade de fenóis totais nas folhas $(A, C)$ e cascas $(B, D)$ com características biométricas de Lafoensia replicata Pohl.

\subsection{Considerações sobre o método de quantificação de fenóis utilizado neste estudo}

Usualmente são utilizados ensaios de precipitação de metais ou proteínas e os métodos colorimétricos para a quantificação de compostos fenólicos de maneira geral [19]. Os métodos colorimétricos são bem reconhecidos e largamente usados para quantificar fenóis totais e, dentre eles, destaca-se o método de Folin-Denis [17]. Contudo, tal reagente não faz distinção entre compostos fenólicos e outros compostos redutores ou antioxidantes, como o ácido ascórbico, formando precipitados que podem interferir na leitura espectrofotométrica [17]. Por conta disso o método Folin-Denis foi modificado para o Folin-Ciocalteau [14], e assim menos propenso as interferências. De forma básica, o reagente é uma solução de íons formados a partir de heteropoliácidos fosfomolibdicos e fosfotungsticos [22]. Esse reagente oxida os compostos fenólicos, reduzindo os ácidos cuja coloração permite determinar a concentração de substâncias fenólicas em extratos vegetais, por exemplo. Diante disso, optou-se por tal metodologia para o presente trabalho e soma-se também o fato da grande quantidade de estudos que empregam essa técnica, por sua facilidade na execução, reprodutibilidade e grande número de dados e informações fornecidas e assim auxiliando na discussão dos resultados encontrados.

\section{CONCLUSÃO}

De acordo com os resultados apresentados, a concentração de fenóis totais não foi influenciada pela altura e circunferência do caule em $L$. replicata e ainda não houve distinção na quantidade desses compostos entre folhas e cascas do caule. Assim, propostas de manejo sustentado para a espécie não podem ser alicerçadas com base nas características biométricas 
pesquisadas aqui. Salienta-se que se deve orientar a coleta de cascas ou folhas da planta para fins curativos somente em indivíduos de grande porte para assim suportar os danos extrativistas.

Considerando-se que não houve distinções nos teores de fenóis totais entre cascas e folhas para a espécie estudada, recomenda-se fortemente a intercalação desses recursos. O uso das folhas pode diminuir a pressão de coleta nas cascas do caule, cuja retirada pode atingir fatalmente o vegetal. Entretanto, entende-se que há limitações possíveis. Foi estudada apenas uma classe (compostos fenólicos) dentre uma diversidade de metabólitos que atuam na identidade farmacológica da planta em questão. Não há garantias de que a eficiência terapêutica será a mesma só porque cascas e folhas apresentaram teores de compostos fenólicos semelhantes. Ou seja, coletar as folhas no intuito de poupar as cascas pode não garantir a eficácia terapêutica.

Apesar de várias pesquisas realizadas sob diferentes abordagens com fenóis totais, a associação dessas informações com o aproveitamento de plantas medicinais é escassa, principalmente para o estado do Piauí. Dessa forma, são necessários mais estudos direcionados à região, marcada pelo encontro entre a caatinga e o cerrado.

\section{AGRADECIMENTOS}

Os autores agradecem aos revisores anônimos que contribuíram efetivamente para a melhoria na redação deste trabalho.

\section{REFERÊNCIAS BIBLIOGRÁFICAS}

1. Carvalho JCT, Gosmann G, Schenkel EP. Compostos fenólicos simples e heterosídeos. In: Simões CMO, Schenkel EP, Gosmann G, Mello JCP, Mentz LA, Petrovick PR, editores, Farmacognosia da planta ao medicamento. 5ed. Porto Alegre/Florianópolis. Editora: UFRGS, 2004.

2. Silva MC, Frizzo SM. Determinação de taninos na casca de Acacia mearnsii De Wild., em diferentes alturas do tronco. Ciência e Natura 1985; 7: $57-61$.

3. Teixeira ML, Soares AR, Scolforo JRS. Variação do teor de tanino da casca de barbatimão [Stryphnodendronadstringens (Mart.) Coville] em 10 locais de Minas Gerais. Ciência e Prática 1990; 14(2): 229-232.

4. Caldeira M V W, Schumacher MV, Santos EM, Viegas J, Pereira JC. Quantificação de tanino em três povoamentos de Acacia mearnsii de Wild. Boletim de Pesquisa Florestal 1998; 37: 81-88.

5. Sobrinho FCB, Almeida ALS, Monteiro JM. Estudo etnofarmacológico sobre Lafoensia replicata Pohl. no leste do Maranhão, Brasil: uma promissora espécie para bioprospecção. Desenvolvimento e Meio Ambiente 2016; 39: 207-216.

6. Monteiro JM, Neto EMFL, Amorim ELC, Strattmann RR, Araújo EL, Albuquerque UP. Teor de taninos em três espécies medicinais arbóreas simpátricas da caatinga. Rev. Árvore 2005; 29(6): 9991005.

7. Piauilino, SAC, Botrel RT, AC Mancin, AM Souza. Estudo fenológico de Lafoensia replicata Pohl. no município de Bom Jesus, Piauí. Scientia Plena 2012, 8(4): 1-5.

8. Galdino PM, Nascimento MVM, Sampaio BL, Ferreira RN, Paula JR, Costa EA. Antidepressant-like effect of Lafoensia pacari A. St.-Hil. ethanolic extract and fractions in mice. J. Ethnopharmacol. 2009; 124: 581-585.

9. Lima PC, Santos MG, Calabrese KS, Silva ALA, Almeida F. Avaliação da capacidade leishmanicida de espécies vegetais do cerrado. Revista de Patologia Tropical 2015; 44(1): 45-55.

10. Galdino MP. Lafoensia pacari A. St. Hil: Identificação de constituintes ativos e avaliação da atividade antidepressiva [Tese] Programa de Pós-Graduação em Farmacologia, Universidade Federal de Santa Catarina, SC; 2015. 124p.

11. Meira RMS. Anatomia foliar e estudos morfológicos em espécies de Lafoensia Vand. (Lythraceae) nativas do Brasil [Tese] Programa de Pós-Graduação em Biologia Vegetal. Unicamp, Campinas, 2000. 
12. Monteiro JM, Souza JSN, Neto EMFL, Scopel K, Trindade EF. Does total tannin content explain the use value of spontaneous medicinal plants from the Brazilian semi-arid region? Rev. Bras. Farmacogn. 2014; 24: 116-123.

13. Vieira LM, Castro CFS, Dias ALB, Silva AR. Fenóis totais, atividade antioxidante e inibição da enzima tirosinase de extratos de Myracrodruon urundeuva Fr. All. (Anacardiaceae). Rev. Bras. Pl. Med. 2015; 17(4): 521-527.

14. Folin O, Ciocalteau V. On tyrosine and tryptophane determination in proteins. J. Biol. Chem. 1927; 73: 424-427.

15. Hagerman AE, Butler LG. Choosing appropriate methods and standards for assaying tannin. J. Chem. Ecol. 1989; 15(6): 1795-1810.

16. Mueller-Harvey I. Analysis of hydrolysable tannins. An. Feed Sci. Technol. 2001; 91: 3-20.

17. Schofield P, Mbugua DM, Pell AN. Analysis of condensed tannins: a review. An. Feed Sci. Technol. 2001; 91(1-2): 21-40.

18. Ayres M, Ayres Junior M, Ayres DL, Santos AAS. Bioestat 2.0: aplicações estatísticas nas áreas das ciências biológicas e médicas. Brasília: Sociedade Civil Mamirauá, CNPq, 2007. 260p.

19. Cabral DLV, Peixoto Sobrinho TJS, Amorim ELC, Albuquerque UP. Relationship of biometric parameters on the concentration of tannins in two medicinal plants: a case study. Boletín Latinoamericano y del Caribe de Plantas Medicinales y Aromáticas 2010; 9(5): 368-376.

20. Sartori CJ, Castro AHF, Mori FA. Teores de fenóis totais e taninos nas cascas de angico-vermelho (Anadenanthera peregrina). Floresta e Ambiente 2014; 21(3): 394-400.

21. Gobbo-Neto L, Lopes NP. Plantas medicinais: fatores de influência no conteúdo de metabólitos secundários. Quím. Nova 2007; 30: 374-381.

22. Neves LC, Alencar SM, Carpes, ST. Determinação da atividade antioxidante e do teor de compostos fenólicos e flavonoides totais em amostras de pólen apícola de Apis mellifera. Braz. J. Food Technol.VII BMCFB, 2009. 